\title{
Posposições e Marcadores Oblíquos em Akuntsú \\ (Tupí)
}

\author{
Postpositions and oblique markers in Akuntsú (Tupí) \\ Carolina Coelho Aragon ${ }^{1}$
}

Recebido em janeiro de 2018

Aceito em março de 2018

\section{Resumo}

O objetivo deste artigo é apresentar uma análise morfológica e semântica das posposições e dos marcadores oblíquos na língua Akuntsú (língua Tupí), discutindo as variedades semânticas desses elementos e suas classificações morfológicas. Para isso, faz-se uma breve menção aos traços tipológicos dessa língua, focando na descrição da morfologia nominal. Assim, resume-se que, em Akuntsú, as informações gramaticais nominais são codificadas por posposições e marcadores oblíquos, tendo como determinantes os nomes, pronomes, demonstrativos e, em alguns casos, advérbios e verbos.

Palavras-chave: Língua Akuntsú. Posposição. Clíticos. Oblíquos. Mofo-semântica.

\section{Abstract}

The main goal of this article is to present a morphological and semantic analysis of the oblique markers and postpositions in Akuntsú (Tupían language), by providing the semantic varieties of these elements and their morphological classifications. In this regard, the typological features of this language are briefly described, focusing on the analyses of the nominal morphology. Thus, it is presented that the nominal grammatical information, in Akuntsú, is signaled by postpositions and oblique markers, which can be nouns, pronouns, demonstratives and, in some cases, adverbs and verbs.

Keywords: Akuntsú Language. Postpositions. Clitics. Obliques. Morpho-semantics.

Os Akuntsú (falantes da língua Akuntsú - tronco Tupí, família Tupari) estão hoje reduzidos a três remanescentes que vivem na Terra Indígena Rio Omerê, no Estado de Rondônia. São monolíngues e ainda mantêm consolidadas suas formas de organização social e suas atividades coletivas com alto grau de autonomia em relação ao Estado e à sociedade brasileira² ${ }^{2}$ Os Akuntsú compartilham a Terra Indígena com o povo Kanoé (língua Isolada). Dentre os três Kanoé que ali vivem, há um adolescente que, após seus seis anos de idade,

\footnotetext{
${ }^{1}$ Doutora em Linguística pela University of Hawaii, 2014. Professora na Universidade Católica de Brasília (UCB)

${ }^{2}$ Definição criada pela CGIIRC/FUNAI para se referir aos povos indígenas de recente contato.
} 
começou a aprender a língua Akuntsú e o português como línguas adicionais ${ }^{3}$.

O objetivo do presente trabalho é apresentar as posposições e marcadores oblíquos na língua Akuntsú. Retrata-se também as variedades de valores semânticos das posposições, bem como dos marcadores oblíquos ${ }^{4}$. Neste artigo, usa-se o termo posposição somente para morfemas livres que ocorrem após os nomes relacionando-os ao verbo ou a outro elemento da construção sintática. Desta forma, na visão aqui abordada, a principal característica que diferencia caso das posposições é o tipo de morfema, i.e., preso ou livre. Essa visão difere de algumas literaturas sobre línguas Tupí que classificam como posposição tanto os morfemas presos quanto os livres que se combinam com os nomes para indicar o tipo de relação que possuem com o núcleo do sintagma.

Em Akuntsú, argumentos nucleares não são marcados por caso, isto é, não há uma marcação de caso nominativo, ergativo ou absolutivo nos nomes desta língua. Já os não-nucleares, recebem clíticos específicos, aqui referidos como marcadores oblíquos, podendo ser cliticizados tanto a um sintagma ou ao seu núcleo.

Com relação aos principais traços tipológicos dessa língua, Aragon (2014) destaca que, sob o ponto de vista morfológico, Akuntsú é, predominantemente, uma língua aglutinativa, com alguns exemplos fusionais. Possui duas grandes classes abertas de palavras, sendo elas as de nomes e verbos. As classes de adjetivos e advérbios são fechadas. Há, também, as classes de palavras lexicais dos numerais/quantificadores, demonstrativos/dêiticos, partículas e interjeições.

Os nomes podem ser combinados com morfemas flexionais e derivacionais. As informações gramaticais são codificadas por posposições e marcadores oblíquos. Já a morfologia derivacional inclui, mas não se limita, aos morfemas que expressam o diminutivo e o aumentativo. Quanto à formação de palavras, há processos de composição e reduplicação.

Já os verbos, esses são divididos em transitivos e intransitivos. Não há verbos de ligação nesta língua. Os morfemas verbais derivacionais incluem, entre outros, morfemas de mudança de valência, que formam construções antipassivas e causativas. Os argumentos nucleares, por sua vez, são expressos por nomes ou pronomes pessoais. Há também uma subclasse de verbos auxiliares e de morfemas direcionais. A negação é expressa por meio de partícula e/ou sufixos, em bases nominais, adjetivais e verbais.

Esta língua é, predominantemente, complemento-núcleo. Objetos precedem verbos e a ordem de palavra padrão é SOV. A ordem básica dos constituintes

\footnotetext{
${ }^{3}$ Consideramos língua adicional toda língua aprendida em fase posterior à L1/Língua Materna.

${ }^{4}$ Os dados que constam neste trabalho foram retirados de Aragon (2014), com as devidas referências. Os demais, sem referência, são de trabalhos de campo da autora realizados nos anos de 2015 e 2016 (retirados de diferentes conversas naturais).
} 
é: $[($ morfemas pronominais $)+$ nomes $+($ morfologia nominal $)+($ objeto $)+$ $($ morfologia verbal $)+$ verbo $+($ morfologia verbal $)+($ auxiliares $)]$.

A fim de discutir o objetivo deste artigo, o organizamos da seguinte forma: na seção 2, apresentamos um resumo da morfologia nominal; na seção 3, descrevemos as posposições e os marcadores oblíquos; e, por fim, na seção 4, as considerações finais são apontadas.

\section{Morfologia nominal}

Em Akuntsú, a classe dos nomes é, morfologicamente, dividida em independentes (alienáveis) e dependentes (inalienáveis). Os nomes independentes são aqueles que representam elementos que não requerem um determinante, como por exemplo, elementos da natureza, animais, plantas, seres humanos, nomes genéricos e artefatos.

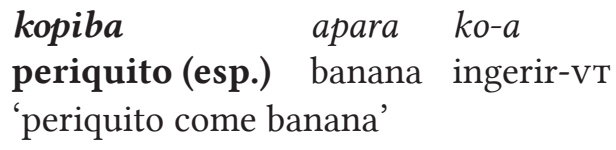

Quanto aos nomes dependentes, esses são inalienáveis, isto é, nomes que requerem um determinante obrigatório, como, por exemplo, elementos que fazem parte de um todo - termos de parentesco, termos que estabelecem uma relação social ou de de posse humana. Quando ocorre essa construção sintática entre o termo determinante e o determinado (núcleo) do sintagma, essa relação requer o uso de um prefixo relacional $t$ - (exemplo (2)) ou ø- (exemplo (3)), os quais indicam a relação de determinação entre os dois termos - determinante e determinado - do sintagma nominal. A utilização do primeiro morfema ou do segundo será feita conforme a classe lexical do núcleo do sintagma.

$$
\begin{array}{ll}
o-i-k o & t-\boldsymbol{e}=n a \\
\text { 1s-NMLZ.OBJ-ingerir } & \mathrm{R}-\mathbf{f o l h a}=\text { ESS } \\
\text { "é para folha da minha comida' }
\end{array}
$$

$$
\begin{array}{lllll}
\text { abatfo } & \text { te }=\varnothing-\boldsymbol{k} \text { wiro } & \text { tea } & \text { ojjpe } & t \text {-ek } \\
\text { avô } & 3 \mathrm{CORR}=\mathrm{R}-\text { recipiente } & \text { existir } & \text { rapé } & \mathrm{R} \text {-casa } \\
\text { 'avô tem o recipiente dele, a casa do rapé (o recipiente que guarda o rapé)' }
\end{array}
$$

Além da classe de nomes dependentes e independentes, temos ainda a classe dos nomes próprios e comuns. Nomes comuns podem ser tanto nomes independentes (4) como dependentes (5):

$\begin{array}{ll}\boldsymbol{k i} \text {-tin } & \boldsymbol{t} \boldsymbol{f o}: \\ \text { líquido/rio-DIM } & \text { IDEO } \\ \text { 'igarapé cresce' } & \end{array}$


(5) $\quad \mathrm{i}=\varnothing-\mathrm{pi} \quad \mathrm{t} \int \mathrm{o}$ :

$3 \mathrm{~s}=\mathrm{R}-\mathrm{pé} \quad$ IDEO

'o pé dela cresce'

Os nomes próprios referem-se à classe dos independentes, apenas. As principais diferenças morfológicas entre nomes próprios e comuns é que apenas os comuns podem ser acompanhados por demonstrativos no mesmo sintagma nominal e podem receber o morfema determinativo, o qual indica especificidade ou familiaridade nos nomes (Rodrigues e Caspar 1957).

Ainda com relação à classe dos nomes, vale salientar que a noção de pluralidade manifesta-se por meio de números, partículas ou por reduplicação. Logo, quando não há nenhum desses morfemas, entende-se que o nome é singular.

\section{Posposições e marcadores oblíquos}

Os marcadores oblíquos são clíticos - definidos como morfemas funcionais, os quais possuem características sintáticas de palavras e combinam-se com um hospedeiro (fonologicamente) (Anderson 2005). Tais clíticos são posicionados dentro de um continuum, entre morfemas livres, que incluem as posposições, e afixos, ditos marcadores de caso (argumentos nucleares, os quais não são encontrados em Akuntsú). Diferentemente, os afixos são tidos como elementos estáveis e que se combinam com classes de palavras específicas. Observe a figura 1, abaixo:

Figura 1: Continuum de posposições, clíticos oblíquos e marcadores de caso

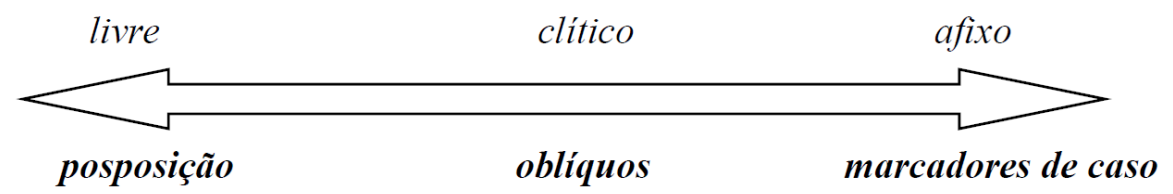

Aragon 2014

Sob o ponto de vista histórico, marcadores nominais (nucleares ou não) podem ter vindo de nomes locacionais ou de verbos seriais (Givón 2001). Revendo as análises sobre o Proto-Tupí, Rodrigues e Cabral (2012) postularam que "(...) the morphological cases found in some Tupían families are traceable from the Proto-Tupían postpositions" (2012:517).

Por conseguinte, a língua Akuntsú é analisada por dispor de marcadores oblíquos (clíticos) e de posposições (morfemas livres), como observa-se na tabela 1 abaixo: 
Tabela 1: Resumo de marcadores oblíquos e posposições (Aragon 2014)

\begin{tabular}{|l|l|l|}
\hline \multicolumn{1}{|c|}{ Tipos } & \multicolumn{1}{|c|}{ Morfemas } & \multicolumn{1}{c|}{ Glossa } \\
\hline \multirow{4}{*}{ Posposição } & etfe & Difuso \\
\cline { 2 - 3 } & ete & Relativo/Comitativo \\
\cline { 2 - 3 } & $p i$ & Inessivo \\
\hline \multirow{4}{*}{ Clítico } & $=(b) \tilde{o}$ & Alativo/Dativo/Instrumental \\
\cline { 2 - 3 } & $=(e) r i$ & Ablativo \\
\cline { 2 - 4 } & $=n a$ & Essivo/Translativo \\
\cline { 2 - 3 } & $=p e$ & Locativo \\
\hline
\end{tabular}

Alguns dos morfemas podem conter mais de um significado semântico, como observado na tabela. Nomes dependentes, independentes, comuns e próprios podem ser combinados aos marcadores oblíquos ou ligados às posposições, bem como pronomes e demonstrativos, como veremos adiante. Os marcadores oblíquos combinam-se aos núcleos de sintagmas nominais, aos núcleos dos sintagmas posposicionais, bem como aos advérbios e, em alguns casos, ao sintagma verbal, como discutiremos a seguir.

\section{Posposições}

etfe - corresponde ao locativo difuso; expressa noção de espaço sem precisão; não corresponde a algum lugar delimitado. Conforme o exemplo abaixo, o falante sabe que entrou um espinho na perna, mas não sabe o local exato:

(6) konit tfe $\quad o=\varnothing-k \dot{p} p$ et $\int e$

espinho vir $1 \mathrm{~s}=\mathrm{R}$-perna DIF

'o espinho veio na minha perna' (Aragon 2014)

No exemplo (7), o falante explica onde deve ir o facão, onde deve ser colocado o instrumento. Enquanto que no exemplo (8), mostra o lugar que deverá queimar, porém sem uma precisão exata do local:

(7) ek et e ka

casa DIF ir

'vai na casa'

(8) $\quad t e=t-e k \quad e t \int e$ poka

3 CORR $=\mathrm{R}$-casa DIF queimar

'queima pela casa dele' 
ete - posposição que corresponde a dois diferentes casos semânticos. Confere uma condição de ponto de referência do estado do predicado ou do processo 'em relação a/no que diz respeito a', indicando o assunto que o falante está se referindo, como observamos nos exemplos abaixo:

(9) te=ø-atap nĩ-ap ete

$3 \mathrm{COR}=\mathrm{R}$-cabelo tecer-NMLZ REL

'é (com relação ao) traçado do cabelo dela' (Aragon 2014)

(10) ajt $\mathrm{i}$ t-et ete?

esposa R-nome REL

'tem (em relação a) um nome de esposa?'

(11) ta i=t-ek ete

DEM $3 \mathrm{~s}=\mathrm{R}$-casa REL

'aquilo é (que diz respeito à) casa dele'

Além disso, também atribui a função de comitativo (exemplo (12)) e associativo (exemplo (13)) 'junto com; em companhia de':

(12) en baj ete

2s buriti REL

'você está com o buriti' (Aragon 2014)

(13) $t e=k^{w} a t-a \quad$ Buko ete

3COR=sair-vT Buquá COM

'ele saiu com Buquá' (Aragon 2014)

$\boldsymbol{p} \boldsymbol{i}$ - posposição que indica o local onde o elemento está imerso ou inserido. A posposição inessiva atribui a um nome o sentido de 'dentro de'. No exemplo (14), o falante está indo ver o interior da casa:

$\begin{array}{ll}o=\varnothing \text {-mepit } t \text {-ek } p i & t \int o p-a \text { on } \\ 1 \mathrm{~s}=\mathrm{R} \text {-filho(a).de.mulher R-casa interior } & \text { ver-VT 1s }\end{array}$

'Eu (vou) ver o interior da casa da minha filha' (Aragon 2014)

No exemplo abaixo, o falante refere-se ao interior da boca:

(15) jẽ pi-at 0

boca interior-INT

'o interior da boca é grande' 


\section{Marcadores oblíquos}

$=(\boldsymbol{b}) \tilde{\boldsymbol{o}}-$ esse clítico expressa os sentidos de: alativo, dativo e instrumental. Observe que esse morfema pode possuir duas formas: $=\tilde{o}$ depois de consonantes $\mathrm{e}=b \tilde{o}$ depois de vogais. Exemplo do alativo, 'a/para/em direção a', encontra-se abaixo:

$=\tilde{0}$

$o=\varnothing$-mepit $e k=\tilde{o} k a$

$1 \mathrm{~s}=\mathrm{R}-$ filho(a).de.mulher casa $=\mathrm{AL}$ ir

'minha filha vai para casa'

Adiante, o alativo expressa um sentido temporal ao ser combinado com advérbios:

$=\mathrm{bõ}$
$k o j o \tilde{p} e=b \tilde{~} i p-a-r a$
noite $=$ AL voltar $-\mathrm{VT}-\mathrm{HAB}$
'À noite volta'

No significado de dativo, agrupam-se os elementos que se referem ao beneficiário de verbos como 'dar' (exemplo (18)), bem como ao destinatário do assunto (exemplo (19)):

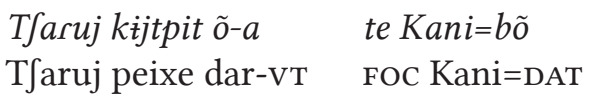

'TSaruj deu peixe para Kani' (Aragon 2014)

(19) (...) ke=bõ nõm on nõm $t=\varnothing$-anam emo ko DEM=DAT não $1 \mathrm{~s}$ não $3 \mathrm{~S}=\mathrm{REL}-$ cabeça também comer '(...) para aquela não, eu não, e (ainda) ela também comeu a cabeça (do peixe)'

Além disso, também tem sentido instrumental, como observado nos exemplos abaixo:

$$
\begin{array}{lll}
\text { eme } n i=b o \tilde{~} & \text { pit } & \text { pit } \\
\text { DEM espinho (tipo)=INS furar } & \text { furar } \\
\text { 'com esse espinho, fura, fura (...)' }
\end{array}
$$


(21) kobore $=b \tilde{o} \quad$ dow

arma $=$ INS IDEO

'matou com a arma'

Ao ser combinado com um sintagma posposicional, o marcador oblíquo indica direcionalidade:

$$
\begin{array}{ll}
o=\varnothing \text {-kere } & \text { at } \int i p i=b \tilde{o} \\
1 \mathrm{~s}=\mathrm{R} \text {-costela } & \text { dor interior }=\mathrm{AL}
\end{array}
$$

'eu tenho dor para dentro da minha costela' (Aragon 2014)

$=(\boldsymbol{e}) \boldsymbol{r} \boldsymbol{i}$ - possui duas variações: =ri depois de vogais e =eri depois de consoantes. No exemplo abaixo, expressa o significado 'de':
kijtpit $\quad \tilde{a} k$
toj-toj
on toj
kijtpit at-a
$\dot{\mathrm{i} k \dot{\mathrm{i}}=r \mathrm{i}}$
peixe assim IDEO-RE
1S IDEO
'eu vou pegar peixe, assim (simula como vai pegar), eu vou pegar o peixe do rio’ (Aragon 2014)

Além do mais, pode também significar causa de um evento. No exemplo (24) abaixo, o mamão é a causa que motivou o falante ficar em casa. No (25) a razão de ter corrido se deu devido à presença de uma onça:

kipek $\quad$ at $\int i=r i \quad$ aj

mamão dor $=\mathrm{ABL}$ ficar

'por causa da dor do mamão, (ela) fica' (Aragon 2014)

(25) ameko=ri o=neme

onça $=\mathrm{ABL} \quad 1 \mathrm{~s}=$ correr

'por causa da onça, eu corri'

Pode também indicar o momento em que um evento começa marcando o seu início, como observado a seguir:
kicre $=r i \quad$ ta baj-a
kiw-kiw
hoje $=\mathrm{ABL}$
DEM limpar-VT
IDEO-RED

'A partir de hoje, aquela limpa isso, rasgando e rasgando' (Aragon 2014)

$=\boldsymbol{n a}$ - bastante frequente na língua, possui a função de essivo e translativo. Assim, o clítico =na é descrito com a abreviação 'essivo-translativo' (ess). Pode indicar o que alguma coisa é, como ela funciona, o estado temporal, como observado em (27). 
(27)

kopiba kwerep-tin=na

periquito (gen.) preto/escuro-DIM=ESS

"é periquito preto pequeno (por enquanto, uma vez que, quando crescer, irá mudar de cor e tamanho)'

$\mathrm{O}$ translativo indica o resultado de uma mudança 'tornando $\mathrm{X}$ ' ou 'mudando $X^{\prime}$ :

(28) $\quad i=t \int a r o=n a$

$3 \mathrm{~s}=$ amarelo $=\mathrm{ESS}$

'é amarelo (ficou amarelo)'

(29) kopiba-tfaro $\quad t-e k=n a$

periquito (esp.) $\quad \mathrm{R}$-casa $=\mathrm{ESS}$

'(vai) ser casa do periquito (cortando o pedaço do pau e explicando no que ele se tornaria)'

No exemplo abaixo, combina-se com o sintagma verbal para indicar o propósito do evento, da ação:

(30) korã $\dot{\mathrm{i}}-\mathrm{ka}=\mathrm{na}$

coró listra-TR=ESS

'(para) desenhar o coró (transformar o coró em desenho)'

Como observado em alguns exemplos acima, esse clítico também é importante em construções com predicado nominal, no qual nomes independentes constituem o núcleo do predicado. Este tipo de construção pode vir acompanhada pelo morfema $=n a$, como atesta-se no exemplo a seguir:

$$
\begin{aligned}
& \text { et } \dot{t}=n a \\
& \text { marico=ESS } \\
& \text { 'é marico' }
\end{aligned}
$$

$=\boldsymbol{p e}$ - expressa a localização precisa de umnome, podendo mostrar exatamente o local em que ele se encontra. É, semanticamente, oposto a posposição locativa difusa etfe. No exemplo (32) abaixo, o falante está chamando a pessoa para ir ao rio buscar água, especificando a parte da margem do rio que deverá ir (usando gestos para que o falante pudesse ver e identificar o local precis):

$$
\begin{aligned}
& \text { iki } \quad \text { at-a en } \dot{t} k \dot{k}=\text { pe } \\
& \text { água/rio pegar-vT } 2 \mathrm{~s} \text { água/rio=LOC } \\
& \text { 'você pega água no rio' (Aragon 2014) }
\end{aligned}
$$


Assim também ocorre nos demais exemplos:

eti $e=t-e k=p e$

marico $2 \mathrm{~s}=\mathrm{R}-\mathrm{casa}=\mathrm{LOC}$

'o marico está na casa'

(34) $k i p t$-ep $e=\varnothing$-anam $=p e$

árvore $\mathrm{R}$-folha $2 \mathrm{~s}=\mathrm{R}$-cabeça $=\mathrm{LOC}$

'a folha está na sua cabeça' (Aragon 2014)

\section{Considerações finais}

Neste artigo, foram apresentadas as características morfológicas e semânticas das posposições e dos marcadores oblíquos da língua Akuntsú, bem como as suas diferenças, classificando-os em morfemas livres e clíticos, respectivamente.

Sob o ponto de vista semântico, alguns dos morfemas podem conter mais de um significado, como por exemplo: a posposição ete 'relativo/comitativo' e os marcadore oblíquos $=(b) \tilde{o}$ 'alativo/dativo/instrumental' e $=n a$ 'essivo/ translativo'. Nomes dependentes, independentes, comuns e próprios, bem como pronomes e demonstrativos podem ser combinados aos marcadores oblíquos ou ligados às posposições. Os marcadores oblíquos combinam-se aos núcleos de sintagmas nominais, aos núcleos do sintagma posposicional, assim como aos advérbios. Mostrou-se também exemplo do marcador oblíquo $=n a$ cliticizado ao sintagma verbal.

\section{Referências}

Anderson, S.R. Aspects of the theory of clitics. Oxford: Oxford Press, 2005.

Aragon, Carolina C. A grammar of Akuntsú, a Tupían language. Tese de doutorado, Universidade do Hawai’i, Manoa, 2014.

Caspar F e Aryon D. Rodrigues. Versuch einer Grammatik der Tupari-Sprache. ms, 1957.

Givón, T. Syntax: a functional-typological introduction, vol. 1. Amsterdam: John Benjamin's, 2001.

Rodrigues, Aryon Dall'Igna and Ana Suelly A., Cabral. Tupían. The Indigenous Languages of South America: A Comprehensive Guide. (The World of Linguistics, vol. 2.), 495-594, ed. by Lyle Campbell and Verónica Grondona. Berlin: Mouton de Gruyter, 2012. 


\section{Abreviações}

ABL Ablativo

AL Alativo

COM Comitativo

CORR Correferencial

DAT Dativo

DEM Demonstrativos

DIF Difuso

DIM Diminutivo

ESS Essivo

FOC Foco

HAB Habitual

IDEO Ideofone

INS Inessivo

INT Intensificador

LOC Locativo

NMLZ Nominalizador

NMLZ.OBJ Nominalizador de objeto

PRJ Projetivo

RED Reduplicação

R Relacional

REL Relativo

S Singular

TR Transitivizador

VT Vogal temática

1 Primeira pessoa

2 Segunda pessoa

3 Terceira pessoa 